\title{
Aşılı Asma Fidanlarına Farklı Yöntemlerle Uygulanan Mikorizaların, Söküm Dönemi Fidan Performansına Etkileri (Vitis vinifera L.)
}

\author{
ilknur KORKUTAL ${ }^{* 1}$, Elman BAHAR ${ }^{1}\left(\mathbb{D}\right.$, Tuğba TEKSÖZ ÖZAKIN ${ }^{2}$ \\ ${ }^{1}$ Namık Kemal Üniversitesi, Ziraat Fakültesi, Bahçe Bitkileri Bölümü - 59030 Tekirdağ \\ ${ }^{2}$ Biotek Biyoteknoloji Tarım - Turgutbey Köyü Banka Tarla Mevkii 13. Pafta 2659 Parsel 39750 Lüleburgaz - \\ Kırklareli
}

Öz: Araştırma Edirne ili Uzunköprü ilçesinde bulunan Teksöz Tarım arazisinde 2015 yılında yürütülmüştür. İçerisinde torf + perlit + yavaş salınımlı gübre bulunan saksılara $(10$ L) dikilen bir yaşlı Alphonse Lavelleé/1103P ve Razakı/1103P aşı kombinasyonuna sahip fidanlarla kurulmuştur. Bu fidanlara kontrol, dikim ortamı, kök, kök+dikim ortamına olmak üzere dört farklı şekilde mikoriza uygulanmıştır. Ticari isimleri Symbion VAM ve Shubhodoya VAM olan iki mikoriza kokteyli seçilmiştir. Deneme, Tesadüf Parsellerinde Faktöriyel Deneme deseni kullanarak kurulmuş ve fidan özellikleri incelenmiştir. Denemede çap özellikleri (anaç, aşı noktası, kalem, ana sürgün, yan sürgün, ortalama genel sürgün); sürgün özellikleri (ana ve ortalama genel sürgün uzunlukları, yaş ve kuru ağılıkları) ve kök özellikleri (ortalama toplam kök, kalın dip kök, ince ve yan kök sayıları; kök uzunluğu, yaş ve kuru ağırlı̆ı, mineral madde analizi) ayrıntılı olarak incelenmiştir. Sonuç olarak Razakı/1103P kombinasyonunda söküm dönemi kriterlerini iyileştirmek amacıyla mikoriza kullanımı önerilmiştir. Ancak Alphonse Lavelleé/1103P kombinasyonunda mikoriza kullanımı fidan başına düşen maliyet açısından tekrar değerlendirilmelidir.

Anahtar Kelimeler: Alphonse Lavalleé, Razakı, 1103P, mikoriza, kök özellikleri

Mycorrhizas Application by Different Methods on Grafted Rooted Vines Sapling Performances in Uprooting Period (Vitis vinifera L.)

\begin{abstract}
Research was established in Teksoz Tarim in the 2015 year. Grapevine saplings (one year old) were planted in $10 \mathrm{~L}$ pots which were filled with peat + perlite + slow release fertilizer mixture. The graft combinations were Alphonse Lavelleé/1103P and Razakl/1103P. Mycorrhizal cocktails (Symbion VAM and Shubhodoya VAM commercial cocktails) were applied four different methods (Control, Planting mixture, Root, Root + Planting mixture) to the young grapevines. This experiment was established the Factorial Design in Randomized Parcels. Diameter characteristics (rootstock, graft union, scion, main shoot, lateral shoot, average general shoot); shoot characteristics (main and average general shoot lengths, main and average fresh and dry weights) and root characteristics (average total root, thin deep root number, thick and lateral root number, root length, root fresh and dry weights, mineral matter analyse) criteria were determined. In conclusion, it's proposed that the use of mycorrhiza cocktails in Razakı/1103P combination, were improved uproot period characteristics. But, in Alphonse Lavelleé/1103P combination; it should be re-evaluate because the put up the cost of saplings.
\end{abstract}

Keywords: Alphonse Lavalleé, Razakı, 1103P, mycorrhizas, root characteristics

GiRiş

Ülkemizde üretilen aşılı-köklü asma fidanı sayısı yeterli değildir ve ülkemizde yaklaşık \%30 düzeyinde bir aşılı asma fidanı açığı oluştuğu söylenebilir (Çelik, 2019). Son yıllarda yeni biyolojik materyaller kullanarak asma fidanı üretimi geliştirilmeye çalışılmakta, bu amaçla bağcılıkta mikorizal preparasyonlar kullanılmaktadır (Kara ve Bağçevli, 2012). Vesikülar Arbüsküler Mikoriza (VAM) kullanımı ile asma kökleri arasında birbirine yarayışlı olan bu ilişkide besin maddesi alımınının artış gösterdiği (Mattheou ve ark., 1994), mikorizanın asmalarda toprak ve kök arasındaki emici yüzeyi artırarak büyümeye yararlı olduğu da bilinmektedir (Schreiner ve Linderman, 2005). Genotiplerin gelişim ve beslenmelerinin mikorizalardan olumlu yönde etkilendiğini Özer (2011), Kara ve ark. (2011a) ve Kara ve Bağçevli (2012) ortaya koymuşlardır. Bavaresco ve ark. (2010), mikoriza uygulaması ile bitkide toplam kuru madde miktarının arttığını tespit etmişlerdir. Balestrini ve ark. (2017), mikoriza karışımı uygulamasının kök yaş ağırlığını değiştirmediğini ancak kontrol grubuna oranla artış sağladığını ortaya koymuşlardır. Eroğlu ve Çelik (2015) mikoriza kokteyl uygulamasının kök sayısı ve Bayram (2000) yaş-kuru kök ağırlığı üzerine etkilerinin istatistiki olarak önemli olmadığını saptamışlardır. Öte yandan Kılıç (2014), kokteyl mikoriza uygulamalarının anaçların kök sayısı, kök çapı, kök yaş ve kuru ağırığı, kök gelişim düzeyine etkilerinin anaçlara göre değiştiğini ifade etmiştir. Özdemir ve ark. (2010), Glomus intraradices'in kök gelişimi üzerine olumlu etki yaptığını kaydetmişlerdir. Augin ve ark. (2004) Glomus aggregatum ile aşılama yapıldığında kök morfolojisinde birinci derece yan köklerde dallanma oluştuğunu ve incelenen anaç köklerinde (110R, 99R ve 101-14Mgt) yeterli fosfor seviyesinin (Meyer ve ark., 2005) bulunduğunu belirlemişlerdir. Düşük fosfor içeriğine sahip

Sorumlu Yazar: ikorkutal@nku.edu.tr Bu çalışma yüksek lisans tez ürünüdür.

Geliş Tarihi: 8 Mart 2019

Kabul Tarihi: 4 Aralık 2019 
topraklarda mikoriza aşılaması yapan Karagiannidis ve ark. (1995), uygulamaların kök kuru ağırlığını artırdığı belirtmişlerdir. Öte yandan Eroğlu (2014), 110R ve 1103P anaçları üzerine Alphonse Lavallée ve Red Globe üzüm çeşitlerini aşılamış, bunlara 3 farklı mikoriza preparasyonu uygulamışlardır. 110R anacı üzerine aşılanan her iki çeşitte de; köklenme oranı, kök sayısı, yaş ve kuru kök ağırlığının 1103P anacına aşılananlardan daha az olduğunu bulmuştur. Bir başka araştırmada Kara ve ark. (2011b), üç mikoriza preparasyonunun asma kök dokularında $\mathrm{P}, \mathrm{Cu}, \mathrm{Mn}, \mathrm{Zn}, \mathrm{B}$ içeriklerinde artışa neden olduğunu görmüşlerdir. Eftekhari ve ark. (2010), mikoriza aşılamasının Kontrol ile uygulama arasında farklılık yarattığını ve ayrıca sürgün uzunluğunda da artışa neden olduğunu (Karagiannidis ve ark., 1995; Nogales ve ark., 2009) belirlemişlerdir. Anzanello ve ark. (2011), VAM'ların anaçların sürgün büyümesini artırdığını görmüşledir. Glomus mosseae'nın sürgün gelişimini olumlu etkilediği Özdemir ve ark. (2010) ve Bayram (2000) tarafından da belirtilmiştir. Ayrıca farklı araştırıcılar Glomus sp. türleri aşılanmış olan anaçların; sürgün uzunluğu ve sürgün çapında artış olduğunu (Bayram, 2000); sürgün kuru ağırlığııın arttığını (Karagiannidis ve ark. 1995); ancak aşı sürgünü uzunluğu (Eroğlu, 2014) ve sürgün kalınlığına (Eroğlu ve Çelik, 2015) istatistiki olarak önemli etki yapmadığını saptamışlardır. Benzer şekilde Kılıç (2014) mikoriza uygulamalarının; sürgün çapı, sürgün uzunluğu, sürgün yaş ve kuru ağırlığına etkilerinin anaçlara göre farklılık gösterdiğini belirlemiştir.

Araştırmanın amacı, farklı yöntemlerle uygulanan mikorizaların bir yaşlı Razakı/1103P ve Alphonse Lavellee/1103P aşı kombinasyonlarına sahip fidanların söküm dönemi performansı üzerine olan etkilerini belirlemektir.

\section{MATERYAL VE YÖNTEM}

Çalışma, Edirne ili Uzunköprü ilçesi Teksöz Tarım fidanlığında $\left(41^{\circ} 15^{\prime} 59.22^{\prime \prime} \mathrm{K}\right.$ ve $\left.26^{\circ} 40^{\prime} 43.17^{\prime \prime} \mathrm{D}\right)$ bir yaşlı fidanlarla 2015 yılı vejetasyon periyodunda yürütülmüştür. Razakı/1103P ve Alphonse Lavalleé/1103P aşı kombinasyonuna sahip 1 yaşındaki fidanlar; içinde torf (Dr. Tarsa Tarım San ve Tic. A.Ş.) + perlit (tarım perliti) ve multicote (Haifa Chemicals Ltd.) bulunan 10 L'lik saksılara dikilmiştir. Bu fidanlar net perdesi ile oluşturulan gölge altında yetiştirilmişler ve biyolojik materyal olarak $\mathrm{T}$. Stanes\&Co. Ltd. firması tarafından üretilmiş olan Symbion VAM (Glomus fasciculatum) ve Cosme Biotech Pvt. Ltd. tarafından üretilen Shubhodaya VAM (üç farklı Glomus sp. mikoriza kokteyli) ticari preparatları uygulanmıştır.

Shubhodaya VAM ve Symbion VAM mikoriza kokteylleri, 4 farklı uygulama ile kuru halde saksılara ilave edilmiştir.

Bunlar;
U 1 (Kontrol): Harca ve fidan köküne herhangi bir mikoriza uygulaması yapılmamış

U 2: Harca mikoriza uygulaması yapılmış, fidan köküne herhangi bir mikoriza uygulaması yapılmamış

U 3: Harca ve fidana mikoriza uygulanmış

U 4: Harca mikoriza uygulaması yapılmamamış, fidan köküne mikoriza uygulaması yapılmıştır.

Denemede iki farklı üzüm çeşidi için, 2 farkı biyolojik materyal (Shubhodaya VAM=Sh-VAM ve Symbion-VAM=SyVAM), 4 farklı uygulama (Uygulama 1=Kontrol, Uygulama 2, Uygulama 3, Uygulama 4) yapılmıştır. Denemede 3 tekerrür ve her tekerrürde 4 fidan olmak üzere, bir biyolojik materyal için 96 adet aşılı köklü Razakı/1103P ve Alphonse Lavalleé/1103P fidanları kullanılmıştır. Bu şekilde denemede kullanılan toplam fidan sayısı 192 adettir. Her mikoriza kokteyline (biyolojik materyal) ait ana etki Alphonse Lavalleé Uygulama Ana Etkisi (ALUAE) ve Razakı Uygulama Ana Etkisi (RUAE) ayrı ayrı belirlenmiştir. Biyolojik Materyal Ana Etkisi (BMAE) ise tekerrür ortalamaları alınarak sunulmuştur.

Fidanların dikimi 23.05.2015 tarihinde yapılmış, Eichhorn ve Lorenz (1977)'ye göre belirlenmiş olan aşamalara göre; fidanlar gelişmesini tamamlayıp (EL 41), ardından yaprak döktükten (EL 43) sonra saksılardan 20.12.2015 tarihinde sökülmüştür. Sökülen fidanlarda; çap özellikleri (anaç, aşı noktası, kalem, ana sürgün, yan sürgün, ortalama genel sürgün); kök özellikleri (ortalama toplam kök, kalın dip kök, ince ve yan kök sayıları; kök uzunluğu, yaş ve kuru ağırlığı, mineral madde analizi) ve sürgün özellikleri (ana ve ortalama genel sürgün uzunlukları, yaş ve kuru ağırlıkları) kriterleri incelenmiştir.

\section{istatistik Analiz}

Tesadüf Parsellerinde Faktöriyel Deneme deseninde kurulmuş olan denemenin istatistiki analizlerinde MSTAT-C istatistik paket programı (MSTAT-C, 1989) ve görülen farklııkları ortaya koymak amacıyla LSD testi (Düzgüneş ve ark., 1983) kullanılmıştır.

\section{BULGULAR VE TARTIŞMA}

\section{Çap özellikleri}

Aşı noktasının $5 \mathrm{~cm}$ altından iki yönlü ölçülen anaç çapı değerleri arasında uygulamalara ve çeşitlere göre istatistiki olarak önemli farklıık oluşturmadığı belirlenmiştir. Ancak $A$. Lavalleé çeşidine uygulanan iki Biyolojik Materyal Ana Etkisi değerlendirildiğinde Sh-VAM (11.36 mm)'ın rakamsal olarak Sy-VAM'dan $(10.83 \mathrm{~mm})$ daha olumlu etki yaptığı belirlenmiştir. Razakı çeşidinde U3 uygulamasının (10.72 $\mathrm{mm}$ ) en yüksek anaç çapı değeri veren doz olduğu belirlenmiştir.

Aşı noktası çapı üzerine uygulamaların etkisinin istatistiki olarak önemli olmadığı görülmüştür (Çizelge 1). Biyolojik 
Çizelge 1. Farklı mikoriza uygulamalarının aşı noktası çapı üzerine etkileri

\begin{tabular}{|c|c|c|c|c|c|c|}
\hline \multirow{2}{*}{$\begin{array}{l}\text { Bitkisel } \\
\text { materyal }\end{array}$} & \multirow[t]{2}{*}{ Biyolojik materyal } & \multicolumn{4}{|c|}{ Uygulamalar } & \multirow{2}{*}{$\begin{array}{l}\text { Biy. Mat. Ana } \\
\text { Etkisi (BMAE) }\end{array}$} \\
\hline & & U $1(\mathrm{~K})$ & U 2 & U 3 & U 4 & \\
\hline \multirow{2}{*}{$\begin{array}{l}\text { Alphonse } \\
\text { Lavalleé }\end{array}$} & Sh-VAM & 22.11 & 20.81 & 18.79 & 21.66 & 20.84 \\
\hline & Sy-VAM & 22.11 & 19.10 & 20.73 & 18.73 & 20.17 \\
\hline \multicolumn{2}{|c|}{$\begin{array}{l}\text { Alphonse Lavalleé Uygulama Ana } \\
\text { Etkisi (ALUAE) }\end{array}$} & 22.11 & 19.95 & 19.76 & 20.19 & - \\
\hline \multirow{2}{*}{ Razakı } & Sh-VAM & 19.06 & 20.14 & 19.87 & 20.36 & 19.85 \\
\hline & Sy-VAM & 19.06 & 17.78 & 18.31 & 19.49 & 18.66 \\
\hline \multicolumn{2}{|c|}{ Razakı Uygulama Ana Etkisi (RUAE) } & 19.06 & 18.96 & 19.09 & 19.92 & - \\
\hline
\end{tabular}

Ö.D. Alphonse Lavalleé; Ö.D. Razakı

Materyal Ana Etkisi bakımından A. Lavalleé çeşidinde ShVAM (20.84 mm) yüksek ve Sy-VAM (20.17 mm) düşük değerleri almıştır. Razakı çeşidinde ise Sh-VAM (19.85 $\mathrm{mm}$ )'ın yüksek ve Sy-VAM (18.66 mm)'ın düşük aşı noktası çapı değerleri aldığı saptanmıştır. Ayrıca Kontrol uygulamasının (U1) A. Lavalleé çeşidinde en yüksek aşı noktası çapı $(22.11 \mathrm{~mm})$ değerini verdiği belirlenmiştir. Bu bulgu Eroğlu ve Çelik (2015)'in mikoriza uygulamalarının aşı yeri çapı üzerine etkilerinin önemli olmadığı bulgusuyla paraleldir.

Kalem çapı üzerine A. Lavalleé Uygulama Ana Etkisi LSD \%5'e göre önemlidir. En yüksek değerin $11.02 \mathrm{~mm}$ ile U1 uygulamasında olduğu saptanmıştır. Biyolojik Materyal Ana Etkisi açısından A. Lavalleé çeşidi $9.61 \mathrm{~mm}$ ile en yüksek kalem çapı değerini Sh-VAM uygulamasıyla vermiştir (Çizelge 2). Razakı çeşidinde Biyolojik Materyal Ana Etkisi'nin Sh-VAM uygulamasında $7.50 \mathrm{~mm}$ Sy-VAM ise 6.85 $\mathrm{mm}$ olduğu saptanmıştır. Razakı Uygulama Ana Etkisi en yüksek $7.91 \mathrm{~mm}$ değeri ile U1 uygulamasından alınmıştır. Korkutal ve ark. (2018)'nın bulgusuyla benzer etkiler görülmüştür.

A. Lavallée çeşidinde tüm uygulamaların etkisi istatistiki olarak LSD \%1 seviyesinde önemli ve Biyolojik Materyal Ana Etkisi yüksek değeri $8.22 \mathrm{~mm}$ ile Sh-VAM uygulamalarından alınmıştır (Çizelge 3). Razakı Uygulama Ana Etkisi ve interaksiyonları istatistiki olarak önemli bulunmamıştır. Bayram (2000)'ın mikoriza uygulanan anaçların sürgün çapında artış olduğu bulgusu ile sonuçlarımızın aynı yönde olmadığı; Kılıç (2014) ile ise aynı yönde olduğu kaydedilmiştir. Her iki çeşitte de Sh-VAM mikoriza kokteyli yüksek ana sürgün çapı değerleri veren biyolojik materyal olmuştur. Ayrıca anaç çapı, kalem çapı ve aşı noktası çapı değerleri yüksek olan $A$. Lavallée çeşidinin Kontrol uygulamasında ana sürgün çapı değeri de yüksek bulunmuştur.

A. Lavalleé Uygulama Ana Etkisi'nin LSD \%1'e göre istatistiki açıdan önemli olduğu; U2, U3 ve U4 uygulamalarının aynı önem grubunda ve kontrol'den yüksek değer aldığı saptanmıştır (Şekil 1). Razakı çeşidinde Biyolojik Materyal Ana Etkisi bakımından Sh-VAM uygulaması $2.81 \mathrm{~mm}$ değerini almıştır. Bulgularımızın mikoriza uygulamalarının yan sürgün çapında olumlu etki yaptığını belirten Kılıç (2014) ile paralel olduğu ortaya konmuştur.

A. Lavalleé çeşidinde Sh-VAM (6.62 mm) biyolojik materyalinin rakamsal olarak Sy-VAM'dan $(6.04 \mathrm{~mm})$ daha olumlu etki yaptığı görülmüştür. Razakı çeşidinde de ShVAM'ın $4.13 \mathrm{~mm}$ olduğu, Sy-VAM'ın ise $3.79 \mathrm{~mm}$ olduğu kaydedilmiştir. Eroğlu (2014) ve Anzanello ve ark. (2011)'nın VAM ile aşılanmış bitkilerin sürgün çapının; uygulanmamışlardan daha iyi olduğunu belirttikleri bulgusuna denememizde ulaşılamamıştır. Bunun farklı mikoriza kokteyllerinin kullanılmış olmasından kaynaklanabileceği düşünülmüştür.

A. Lavalleé çeşidinde incelene tüm çap özellikleri Kontrol'de en yüksek bulunmuş; yapılan mikoriza uygulamalarının ise çap özelliklerini pozitif etkilemediği belirlenmiştir. Razakı çeşidinde ise çap özellikleri üzerine pozitif etkiler U3 ve U4 uygulamaları ve Sh-VAM'dan alınmıştır. Bu değişen etkilerin çeşit farkından kaynaklanmış olabileceği düşünülmüştür.

Çizelge 2. Farklı mikoriza uygulamalarının kalem çapı üzerine etkileri

\begin{tabular}{|c|c|c|c|c|c|c|}
\hline \multirow{2}{*}{$\begin{array}{l}\text { Bitkisel } \\
\text { materyal }\end{array}$} & \multirow[t]{2}{*}{ Biyolojik materyal } & \multicolumn{4}{|c|}{ Uygulamalar } & \multirow{2}{*}{$\begin{array}{l}\text { Biy. Mat. Ana } \\
\text { Etkisi (BMAE) }\end{array}$} \\
\hline & & U $1(\mathrm{~K})$ & U 2 & U 3 & U 4 & \\
\hline \multirow{2}{*}{$\begin{array}{l}\text { Alphonse } \\
\text { Lavalleé }\end{array}$} & Sh-VAM & 11.02 & 9.83 & 8.60 & 8.99 & 9.61 \\
\hline & Sy-VAM & 11.02 & 8.08 & 8.42 & 7.36 & 8.72 \\
\hline \multicolumn{2}{|c|}{$\begin{array}{l}\text { Alphonse Lavalleé Uygulama Ana } \\
\text { Etkisi (ALUAE) }\end{array}$} & $11.02 a$ & $8.95 a b$ & $8.51 b$ & $8.17 b$ & - \\
\hline \multicolumn{2}{|c|}{ Sh-VAM } & 7.91 & 8.31 & 6.52 & 7.27 & 7.50 \\
\hline \multicolumn{2}{|r|}{ Sy-VAM } & 7.91 & 6.04 & 6.51 & 6.95 & 6.85 \\
\hline \multicolumn{2}{|c|}{ Razakı Uygulama Ana Etkisi (RUAE) } & 7.91 & 7.18 & 6.52 & 7.11 & - \\
\hline
\end{tabular}

ALUAE \%5 LSD = 2.113822 (italik verilmiştir); Ö.D. Razakı 
Çizelge 3. Farklı mikoriza uygulamalarının ana sürgün çapı üzerine etkileri

\begin{tabular}{|c|c|c|c|c|c|c|}
\hline \multirow{2}{*}{$\begin{array}{l}\text { Bitkisel } \\
\text { materyal }\end{array}$} & \multirow[t]{2}{*}{ Biyolojik materyal } & \multicolumn{4}{|c|}{ Uygulamalar } & \multirow{2}{*}{$\begin{array}{l}\text { Biy. Mat. Ana } \\
\text { Etkisi (BMAE) }\end{array}$} \\
\hline & & U $1(\mathrm{~K})$ & U 2 & U 3 & U 4 & \\
\hline \multirow{2}{*}{$\begin{array}{l}\text { Alphonse } \\
\text { Lavalleé }\end{array}$} & Sh-VAM & $9.84 \mathrm{a}$ & $8.18 \mathrm{~b}$ & $8.16 \mathrm{~b}$ & $6.70 \mathrm{c}$ & $8.22 \mathrm{~A}$ \\
\hline & Sy-VAM & 9.84 a & $6.33 c$ & $5.63 \mathrm{c}$ & $5.80 \mathrm{c}$ & $6.90 \mathrm{~B}$ \\
\hline \multicolumn{2}{|c|}{$\begin{array}{l}\text { Alphonse Lavalleé Uygulama Ana } \\
\text { Etkisi (ALUAE) }\end{array}$} & $9.84 a$ & $7.25 b$ & $6.89 b c$ & $6.25 c$ & - \\
\hline \multirow{2}{*}{ Razakı } & Sh-VAM & 5.31 & 5.37 & 5.15 & 5.97 & 5.45 \\
\hline & Sy-VAM & 5.31 & 4.82 & 5.40 & 5.16 & 5.17 \\
\hline \multicolumn{2}{|c|}{ Razakı Uygulama Ana Etkisi (RUAE) } & 5.31 & 5.10 & 5.28 & 5.56 & - \\
\hline
\end{tabular}

BMAE \%1 Önemli (Büyük harfle verilmiştir), ALUAE \%1 LSD = 0.9045554 (italik verilmiştir). BMAE x ALUAE \%1 LSD = 1.279235; Ö.D. Razakı

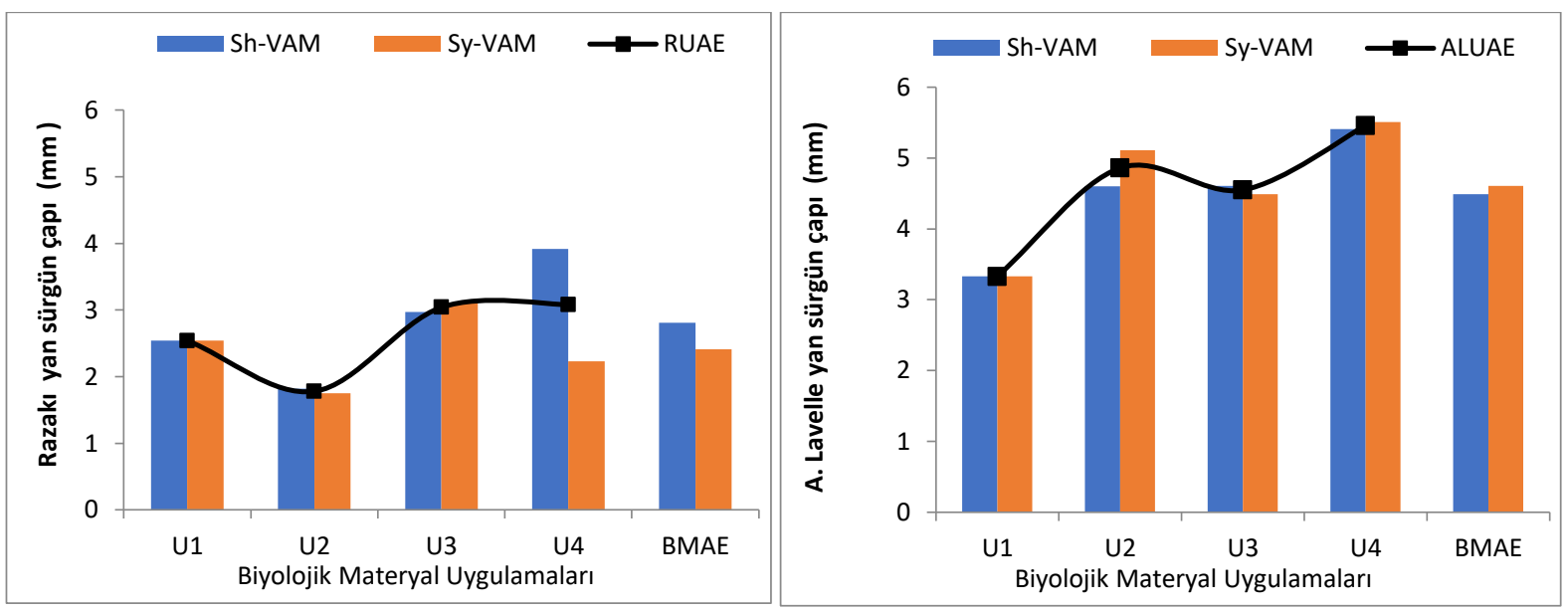

Şekil 1. Her iki mikoriza uygulamasının Razakı ve A. Lavalleé çeşitlerinin yan sürgün çapı etkileri [Sh-VAM: U 1 (Kontrol=VAM yok). U 2 (Harca VAM). U 3 (Fidana VAM). U 4 (Harca+Fidana VAM); Sy-VAM: U 1 (Kontrol=VAM yok). U 2 (Harca VAM). U 3 (Fidana VAM). U 4 (Harca+Fidana VAM)]

\section{Sürgün Özellikleri}

Biyolojik Materyal Ana Etkisi bakımından A. Lavalleé çeşidi en yüksek Sy-VAM $(138.82 \mathrm{~cm})$ Razakı çeşidinde ise en yüksek Sh-VAM (115.19 cm) ana sürgün uzunluğu değerlerini aldığı belirlenmiştir. Razakı Uygulama Ana Etkisi açısından ise en yüksek ana sürgün uzunluğu değerine U4 $(124.52 \mathrm{~cm})$ uygulaması ile erişilmiştir. Sonuçlarımız Eroğlu ve Çelik (2015), Eroğlu (2014) ve Kara ve ark. (2011a) mikoriza uygulamalarının Kontrol'e göre sürgün uzunluğuna etkilerinin istatistiki olarak önemsiz olduğu ve Kılıç (2014)'ın, anaçlara göre farklılık gösterdiği bulgusuyla da benzerdir. Ancak bulgularımızın Kara ve ark. (2011b)'nın mikoriza uygulamaların sürgün uzunluğunu önemli şekilde arttırdığı bulgusu ile farklı yönde olduğu belirlenmiştir. Yapılan uygulamaların her iki çeşitte de aynı etkiyi göstermediği, bunun uygulama yapılan aşılı-çelik ve kullandığımız fidan yaşından kaynaklandığı söylenebilir.

A. Lavalleé çeşidinde en olumlu etkiyi Sy-VAM $(34.31 \mathrm{~cm})$ biyolojik materyalinin yaptığı görülmüştür. A. Lavalleé Uygulama Ana Etkisi'nin de LSD \%5'e göre önemli olduğu ve U2'nin $(79.24 \mathrm{~cm})$ en yüksek yan sürgün uzunluğu değerini aldığı belirlenmiştir (Çizelge 4). Bulgularımız Karagiannidis ve ark. (1995) ile benzerdir.

Ortalama genel sürgün uzunluğu açısından U2 uygulamalarının $(88.34 \mathrm{~cm}$ ) A. Lavalleé Uygulama Ana Etkisi bakımından en yüksek rakamsal değeri aldığı belirlenmiştir. Razakı Uygulama Ana Etkisi incelendiğinde genel sürgün uzunluğu en yüksek U3 $(81.58 \mathrm{~cm})$ uygulamasından alınmıştır. A. Lavalleé çeşidinde Sh-VAM X U2 kombinasyonu $(98.55 \mathrm{~cm})$ en yüksek; Razakı çeşidinde ise Sh-VAM X U4 $(89.02 \mathrm{~cm})$ en yüksek genel sürgün uzunluğu değerlerini almıştır. Eroğlu ve Çelik (2015)'in, uygulamaların Kontrol'e göre sürgün uzunluğuna etkilerinin önemsiz olduğu bulgusu sonuçlarımızla paraleldir.

İstatistiki olarak önemli olmamakla birlikte yan sürgün yaş ağırlığına Razakı Uygulama Ana Etkisi bakımından U3 uygulamasının (5.51 g) en yüksek rakamsal değeri verdiği görülmüştür. A. Lavalleé Uygulama Ana Etkisi'nin en yüksek yan sürgün yaş ağırlık değerinin ise U2 (4.97 g) uygulamasından alındığı belirlenmiştir. Bayram (2000)'ın, mikoriza kullanımının sürgün yaş ağırlığı artırdığı bulgusu 
Çizelge 4. Farklı mikoriza uygulamalarının yan sürgün uzunluğu üzerine etkileri

\begin{tabular}{|c|c|c|c|c|c|c|}
\hline \multirow{2}{*}{$\begin{array}{l}\text { Bitkisel } \\
\text { materyal }\end{array}$} & \multirow[t]{2}{*}{ Biyolojik materyal } & \multicolumn{4}{|c|}{ Uygulamalar } & \multirow{2}{*}{$\begin{array}{l}\text { Biy. Mat. Ana } \\
\text { Etkisi (BMAE) }\end{array}$} \\
\hline & & U $1(\mathrm{~K})$ & U 2 & U 3 & U 4 & \\
\hline \multirow{2}{*}{$\begin{array}{l}\text { Alphonse } \\
\text { Lavalleé }\end{array}$} & Sh-VAM & $33.44 \mathrm{~b}$ & $132.27 \mathrm{a}$ & $17.77 b$ & $37.61 b$ & $30.27 \mathrm{~B}$ \\
\hline & Sy-VAM & $33.44 \mathrm{~b}$ & $26.22 \mathrm{~b}$ & $54.33 \mathrm{~b}$ & $23.27 b$ & $34.31 \mathrm{~A}$ \\
\hline \multicolumn{2}{|c|}{$\begin{array}{l}\text { Alphonse Lavalleé Uygulama Ana } \\
\text { Etkisi (ALUAE) }\end{array}$} & $33.44 b$ & $79.24 a$ & $36.05 b$ & $30.44 b$ & - \\
\hline \multirow{2}{*}{ Razakı } & Sh-VAM & 31.92 & 14.89 & 45.33 & 48.77 & 35.23 \\
\hline & Sy-VAM & 31.92 & 27.00 & 51.00 & 26.89 & 34.20 \\
\hline \multicolumn{2}{|c|}{ Razakı Uygulama Ana Etkisi (RUAE) } & 31.92 & 20.94 & 48.16 & 37.83 & - \\
\hline \multicolumn{7}{|c|}{ 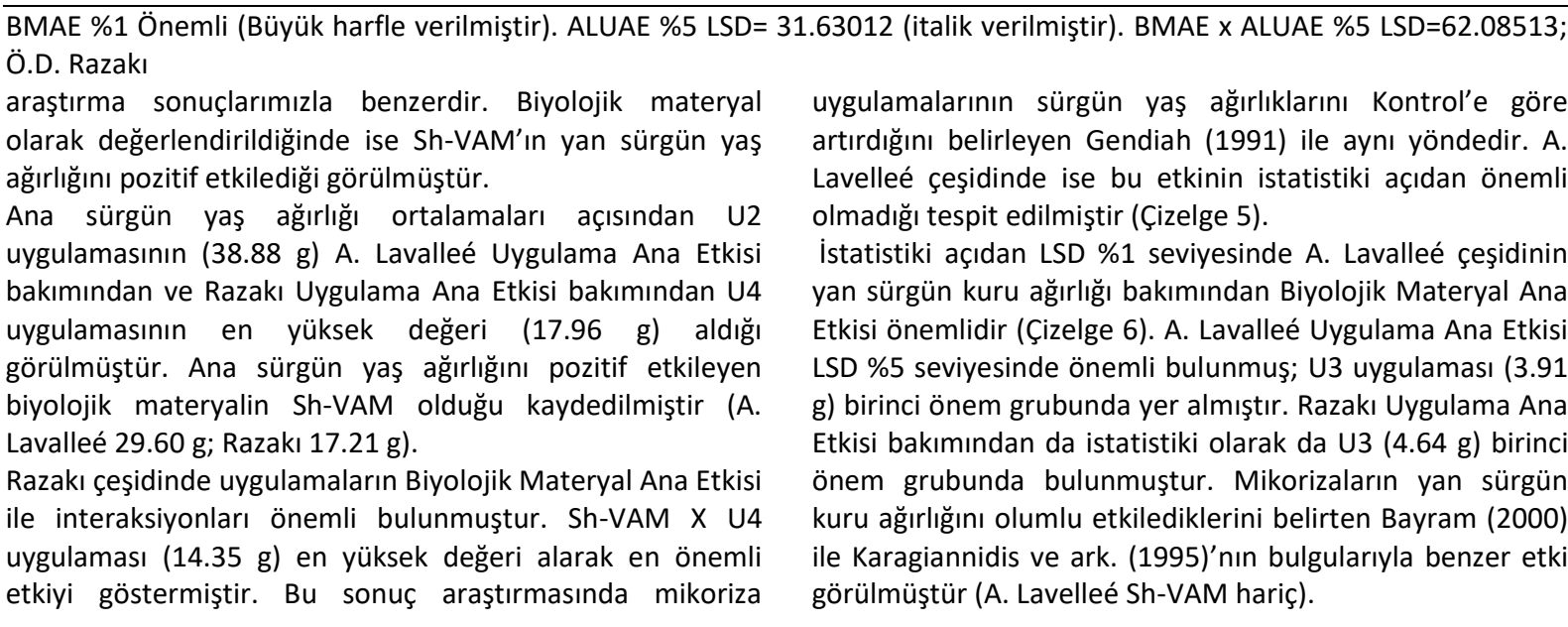 } \\
\hline \multicolumn{7}{|c|}{ Çizelge 5. Farklı mikoriza uygulamalarının ortalama genel sürgün yaş ağırlığı üzerine etkileri } \\
\hline \multirow{2}{*}{$\begin{array}{l}\text { Bitkisel } \\
\text { materyal }\end{array}$} & \multirow[t]{2}{*}{ Biyolojik materyal } & \multicolumn{4}{|c|}{ Uygulamalar } & \\
\hline & & $\mathrm{U} 1(\mathrm{~K})$ & U 2 & U 3 & U 4 & Etkisi (BMAE) \\
\hline \multirow{2}{*}{$\begin{array}{l}\text { Alphonse } \\
\text { Lavalleé }\end{array}$} & Sh-VAM & 15.02 & 27.98 & 13.07 & 12.33 & 17.10 \\
\hline & Sy-VAM & 15.02 & 15.88 & 13.78 & 16.36 & 15.26 \\
\hline \multicolumn{2}{|c|}{$\begin{array}{l}\text { Alphonse Lavalleé Uygulama Ana } \\
\text { Etkisi (ALUAE) }\end{array}$} & 15.02 & 21.93 & 13.42 & 14.34 & - \\
\hline \multirow{2}{*}{ Razakı } & Sh-VAM & $8.72 \mathrm{~b}$ & $7.66 \mathrm{~b}$ & $10.54 \mathrm{ab}$ & $14.35 \mathrm{a}$ & 10.32 \\
\hline & Sy-VAM & $8.72 \mathrm{~b}$ & $7.84 \mathrm{~b}$ & $11.20 \mathrm{ab}$ & $7.67 \mathrm{~b}$ & 8.86 \\
\hline \multicolumn{2}{|c|}{ Razakı Uygulama Ana Etkisi (RUAE) } & 8.72 & 7.75 & 10.87 & 11.01 & - \\
\hline
\end{tabular}

Alphonse Lavelle: Ö.D.; Razakı: BMAE x RUAE \%5 LSD=4.160371

Çizelge 6. Farklı mikoriza uygulamalarının yan sürgün kuru ağırlığı üzerine etkileri

\begin{tabular}{|c|c|c|c|c|c|c|}
\hline \multirow{2}{*}{$\begin{array}{l}\text { Bitkisel } \\
\text { materyal }\end{array}$} & \multirow[t]{2}{*}{ Biyolojik materyal } & \multicolumn{4}{|c|}{ Uygulamalar } & \multirow{2}{*}{$\begin{array}{l}\text { Biy. Mat. Ana Etkisi } \\
\text { (BMAE) }\end{array}$} \\
\hline & & U $1(\mathrm{~K})$ & U 2 & U 3 & U 4 & \\
\hline \multirow{2}{*}{$\begin{array}{l}\text { Alphonse } \\
\text { Lavalleé }\end{array}$} & Sh-VAM & $3.27 \mathrm{~b}$ & $2.40 \mathrm{~b}$ & $2.10 \mathrm{~b}$ & $3.07 \mathrm{~b}$ & $2.71 \mathrm{~B}$ \\
\hline & Sy-VAM & 3.27 b & $3.13 \mathrm{~b}$ & $5.72 \mathrm{a}$ & $2.72 \mathrm{~b}$ & $3.71 \mathrm{~A}$ \\
\hline \multicolumn{2}{|c|}{$\begin{array}{l}\text { Alphonse Lavalleé Uygulama Ana } \\
\text { Etkisi (ALUAE) }\end{array}$} & $3.27 a b$ & $2.76 b$ & $3.91 a$ & $2.89 b$ & - \\
\hline \multirow{2}{*}{ Razakı } & Sh-VAM & 2.21 & 0.78 & 3.72 & 3.23 & 2.48 \\
\hline & Sy-VAM & 2.21 & 3.04 & 5.56 & 2.08 & 3.27 \\
\hline \multicolumn{2}{|c|}{ Razakı Uygulama Ana Etkisi (RUAE) } & $2.21 b$ & $1.91 b$ & $4.64 a$ & $2.65 b$ & - \\
\hline
\end{tabular}

Alphonse Lavallee BMAE \%1 LSD= 2.088039 (büyük harfle verilmiştir). ALUAE \%5 LSD= 1.06378 (italik verilmiştir). ALUAE X BMAE \%1 LSD= 2.08; Razakı RUAE \%1 LSD= 1.66 (italik verilmiştir) 
Ana sürgün kuru ağırlığı açısından U4 uygulamasının (14.53 g) A. Lavalleé Uygulama Ana Etkisi bakımından yüksek rakamsal değeri aldığı görülmüştür. Razakı Uygulama Ana Etkisi bakımından da U3 uygulamasında en yüksek değeri $(8.20$ g) verdiği belirlenmiştir. Yaptıkları mikoriza uygulamalarının kontrol grubuna göre ana sürgün kuru ağırlığını olumlu yönde etkilediğini ifade eden Bayram (2000) ile Augin ve ark. (2004)'nın bulguları ile aynı yönde olmadığı, bunun farklı anaç kullanımından kaynaklanmış olabileceği düşünülmüştür.

Her iki çeşit için ortalama genel sürgün kuru ağırlığı üzerine en olumlu etkiyi Sy-VAM (A. Lavalleé 9.09 g; Razakı $5.31 \mathrm{~g}$ ) biyolojik materyalinin yaptığı görülmüştür. A. Lavalleé ve Razakı çeşitlerinde Fidana VAM (U3) uygulamasının (8,73 g ve $6.42 \mathrm{~g}$ ) en yüksek ortalama genel sürgün kuru ağırlığı değerlerine eriştiği belirlenmiştir.

\section{Kök özellikleri}

A. Lavalleé Uygulama Ana Etkisi bakımından U4 uygulamasının (8.80 adet) yüksek rakamsal değeri aldığı görülmüştür. Razakı Uygulama Ana Etkisi incelendiğinde U3 uygulamasının en yüksek değeri (5.20 adet) aldığı saptanmıştır. Biyolojik Materyal Ana Etkisi açısından ise ShVAM (5.03 adet) ortalama kök sayısı değerini aldığı belirlenmiştir. Elde edilen Sh-VAM bulguları ile Kavak (2006), Özdemir ve ark. (2010) ve Kılıç (2014)'ın mikoriza uygulamalarının kök sayısını artırdığı bulgusuyla A. Lavalleé çeşidi açısından benzerdir (Şekil 2).

A. Lavalleé Uygulama Ana Etkisi istatistiki olarak LSD \%1'e göre önemlidir, buna göre Kontrol (4.55 adet) en fazla ortalama kalın dip kök sayısına sahiptir. A. Lavalleé çeşidinde Sh-VAM X U1 ve Sy-VAM X U1 interaksiyonlarının da 4.55 adet değeri ile en yüksek etki yapan interaksiyonlar olduğu kaydedilmiştir (Şekil 3). Razakı Uygulama Ana Etkisi istatistiki olarak önemli olmamakla beraber U4 uygulamasının en fazla ortalama kalın dip kök sayısına sahip olduğu saptanmıştır.
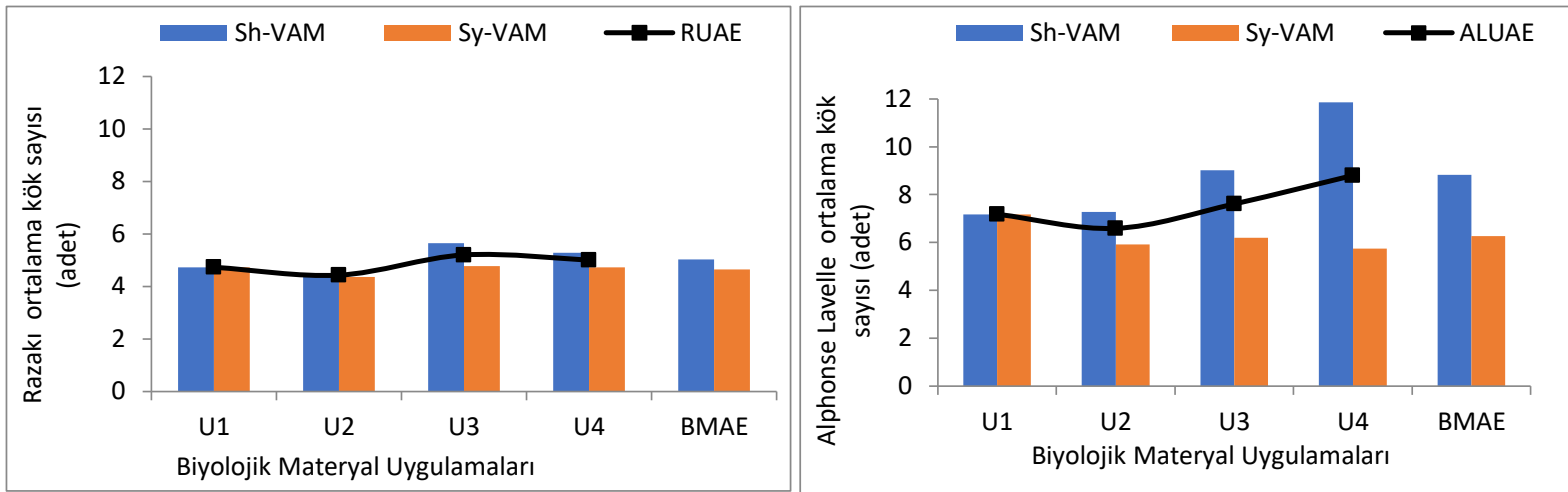

Şekil 2. Her iki mikoriza uygulamasının Razakı ve A. Lavalleé çeşitlerinin ortalama kök sayısına etkileri [Sh-VAM: U 1 (Kontrol=VAM yok). U 2 (Harca VAM). U 3 (Fidana VAM). U 4 (Harca+Fidana VAM); Sy-VAM: U 1 (Kontrol=VAM yok). U 2 (Harca VAM). U 3 (Fidana VAM). U 4 (Harca+Fidana VAM)]

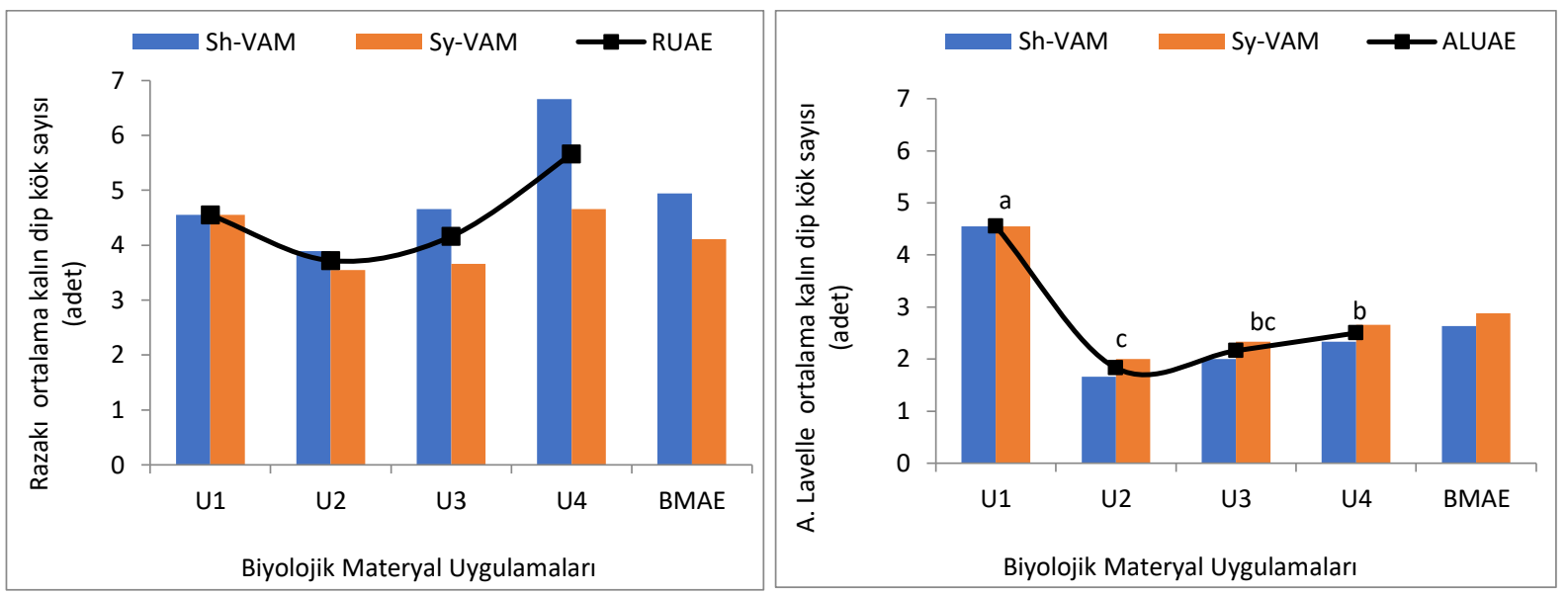

Şekil 3. Her iki mikoriza uygulamasının Razakı ve A. Lavalleé çeşitlerinin ortalama kalın dip kök sayısına etkileri [Sh-VAM: U 1 (Kontrol=VAM yok). U 2 (Harca VAM). U 3 (Fidana VAM). U 4 (Harca+Fidana VAM); Sy-VAM: U 1 (Kontrol=VAM yok). U 2 (Harca VAM). U 3 (Fidana VAM). U 4 (Harca+Fidana VAM)] 
A. Lavelleé çeşidinde Biyolojik Materyal Ana Etkisi'nin istatistiki açıdan LSD \%1 düzeyinde önemli olduğu ShVAM'ın 26.41 adet ince kök sayısı değeri ile en yüksek değeri aldığı kaydedilmiştir. A. Lavalleé Uygulama Ana Etkisi incelendiğinde yine U4 uygulamasının (26.33 adet) ortalama ince dip kök sayısını en artırıcı etkiye sahip olduğu belirlenmiştir. Araştırmamızda biyolojik materyal uygulamalarının ince dip kök sayılarını nispeten artırdığı belirlenmiş (A. Lavelleé Sy-VAM hariç) ve Özdemir ve ark. (2010) ile benzerlik gösterdiği ortaya konmuştur.

A. Lavalleé çeşidine uygulanan iki Biyolojik Materyal Ana Etkisi'nin istatistiki açıdan önemli olmadığı ve en olumlu etkiyi Sh-VAM (0.51 adet) biyolojik materyalinin yaptığı görülmüştür. Benzer şekilde Razakı çeşidinde de Sh-VAM (1.25 adet) tespit edilmiştir. A. Lavelleé çeşidinde mikoriza uygulamaları kalın kök sayısını azaltmıştır. Benzer etki Kontrol ile karşılaştırıldığında Razakı çeşidinde de görülmüştür. Bu istenilen bir durumdur.

Her iki çeşitte de ortalama ince yan kök sayısı bakımından istatistiki olarak bir farklılık bulunmamıştır, ancak A. Lavalleé çeşidinde Biyolojik Materyal Ana Etkisi açısından Sy-VAM (6.15 adet)'ın Sh-VAM'dan (3.86 adet) daha olumlu etki yaptığı belirlenmiştir. A. Lavellee çeşidinden alınan bulgularımızın Kılıç (2014) ile Augin ve ark. (2004) mikoriza aşılamasıyla birinci derecede yan köklerde dallanma olduğunu saptadıkları bulguları ile benzer olduğu görülmüştür.

A. Lavalleé çeşidinde en olumlu etki Sh-VAM $(46.86 \mathrm{~cm})$ biyolojik materyalinden alınmıştır ve A. Lavalleé Uygulama
KORKUTAL i, BAHAR E, TEKSÖZ ÖZAKIN T Ana Etkisi istatistiki olarak da önemli bulunmuştur (Çizelge 7). Razakı Uygulama Ana Etkisi ve interaksiyonları istatistiki olarak önemli bulunmamıştır. Anzanello ve ark. (2011), Kavak (2006) ve Özdemir ve ark. (2010) ile VAM'ların kök uzunluğunu pozitif şekilde etkilediği bulgusuyla A. Lavalleé çeşidi bulgularının benzer olduğu; öte yandan Kara ve Bağçevli (2012)'nin bazı mikoriza uygulamalarının kök uzunluğunu etkilemediği bulgusu ile de Razakı çeşidinin benzer olduğu saptanmıştır.

A. Lavalleé çeşidinde Biyolojik Materyal Ana Etkisi bakımından en olumlu etkiyi Sy-VAM (22.74 g)'ın yaptığı belirlenmiştir. Razakı çeşidinde aynı etki yine Sy-VAM uygulamasından (17.79 g) alınmıştır. Bulgularımızın Bayram (2000), Kılıç (2014), Eroğlu (2014), Eroğlu ve Çelik (2015) ve Balestrini ve ark. (2017)'nın mikoriza uygulamalarının kök yaş ağırlığına etkilerinin önemsiz olduğu bulgusuyla paralel olduğu belirlenmiştir.

Yan kök yaş ağırlığı açısından her iki çeşitte de istatistiki olarak bir farklılık yoktur; yan kök yaş ağırlığı yapılan uygulamalarla Kontrole nazaran Razakı çeşidinde azalmış, A. Lavallee çeşidinde ise nispeten artmıştır

Dip kök yaş ağırlığı bakımından Biyolojik Materyal Ana Etkisi LSD \%1'e göre istatistiki açıdan önemlidir; Sy-VAM'dan $37.39 \mathrm{~g}$ değeri ile en yüksek veri alınmıştır (Çizelge 8). Razakı çeşidinde Biyolojik Materyal Ana Etkisi'nin Sh-VAM uygulamasında (23.79 g) Sy-VAM'a (21.77 g) göre yüksek olduğu kaydedilmiştir. Razakı çeşidine ait bulgularımızın Eroğlu ve Çelik (2015) ile paralel olduğu söylenebilir.

Çizelge 7. Farklı mikoriza uygulamalarının her iki çeşitte kök uzunluğu üzerine etkileri

\begin{tabular}{|c|c|c|c|c|c|c|}
\hline \multirow{2}{*}{$\begin{array}{l}\text { Bitkisel } \\
\text { materyal }\end{array}$} & \multirow[t]{2}{*}{ Biyolojik materyal } & \multicolumn{4}{|c|}{ Uygulamalar } & \multirow{2}{*}{$\begin{array}{l}\text { Biy. Mat. Ana } \\
\text { Etkisi (BMAE) }\end{array}$} \\
\hline & & U $1(\mathrm{~K})$ & U 2 & U 3 & U 4 & \\
\hline \multirow{2}{*}{$\begin{array}{l}\text { Alphonse } \\
\text { Lavalleé }\end{array}$} & Sh-VAM & $52.36 \mathrm{ab}$ & $45.00 \mathrm{ab}$ & $42.61 \mathrm{~b}$ & $47.50 \mathrm{ab}$ & $46.86 \mathrm{~A}$ \\
\hline & Sy-VAM & $52.36 \mathrm{ab}$ & $20.00 \mathrm{c}$ & $47.83 \mathrm{ab}$ & 57.05 a & $39.81 \mathrm{~B}$ \\
\hline \multicolumn{2}{|c|}{$\begin{array}{l}\text { Alphonse Lavalleé Uygulama Ana } \\
\text { Etkisi (ALUAE) }\end{array}$} & $52.36 a$ & $23.50 b$ & $45.22 a b$ & $52.27 a$ & - \\
\hline \multirow{2}{*}{ Razakı } & Sh-VAM & 53.22 & 52.89 & 54.22 & 11.42 & 42.93 \\
\hline & Sy-VAM & 53.22 & 54.89 & 56.50 & 50.55 & 53.79 \\
\hline \multicolumn{2}{|c|}{ Razakı Uygulama Ana Etkisi (RUAE) } & 53.22 & 53.89 & 55.36 & 30.98 & - \\
\hline \multicolumn{7}{|c|}{$\begin{array}{l}\text { A. Lavalleé BMAE \%1 Önemli (büyük harfle verilmiştir). ALUAE \%1 LSD=9.48 } \\
\text { 13.40; Ö.D. Razakı } \\
\text { Çizelge 8. Farklı mikoriza uygulamalarının dip kök yaş ağırlığı üzerine etkileri }\end{array}$} \\
\hline \multirow{2}{*}{$\begin{array}{l}\text { Bitkisel } \\
\text { materyal }\end{array}$} & \multirow[t]{2}{*}{ Biyolojik materyal } & Uygulamalar & & & & \multirow{2}{*}{$\begin{array}{l}\text { Biy. Mat.Ana Etkisi } \\
\text { (BMAE) }\end{array}$} \\
\hline & & U $1(\mathrm{~K})$ & U 2 & U 3 & U 4 & \\
\hline \multirow{2}{*}{$\begin{array}{l}\text { Alphonse } \\
\text { Lavalleé }\end{array}$} & Sh-VAM & 38.50 & 15.48 & 18.01 & 19.17 & $22.79 \mathrm{~B}$ \\
\hline & Sy-VAM & 38.50 & 45.73 & 37.80 & 27.53 & $37.39 \mathrm{~A}$ \\
\hline \multicolumn{2}{|c|}{$\begin{array}{l}\text { Alphonse Lavalleé Uygulama Ana } \\
\text { Etkisi (ALUAE) }\end{array}$} & 38.50 & 30.61 & 27.90 & 23.35 & - \\
\hline \multirow{2}{*}{ Razakı } & Sh-VAM & 22.25 & 21.50 & 26.95 & 24.47 & 23.79 \\
\hline & Sy-VAM & 22.25 & 26.44 & 22.16 & 16.25 & 21.77 \\
\hline \multicolumn{2}{|c|}{ Razakı Uygulama Ana Etkisi (RUAE) } & 22.25 & 23.97 & 24.56 & 20.36 & - \\
\hline
\end{tabular}

A. Lavalleé BMAE LSD \%1 önemli (Büyük harfle gösterilmiştir); Ö.D. Razakı 
A. Lavalleé Sy-VAM X U3 (7.85 g) ve Razakı Sh-VAM X U4 (5.86 g) ile en yüksek etkiye sahip olduğu saptanmıştır. Bayram (2000), Kara ve ark. (2011b), Kılıç (2014), Eroğlu ve Çelik (2015), ve Balestrini ve ark. (2017)'nın kök kuru ağırlığı üzerine mikoriza uygulamalarının istatistiki olarak önemli bir etki yapmadığı bulgusuyla benzer sonuçlar elde etmiştir. Biyolojik Materyal Ana Etkisi bakımından A. Lavalleé çeşidinde yüksek Sh-VAM (3.53 g) ve Razakı çeşidinde ise yüksek Sh-VAM (3.78 g) yan kök kuru ağırlığı değerleri alınmıştır. Bulgularımızın mikoriza uygulamasının kök kuru ağırlığına etkisi olmadığını belirten Bayram (2000) ile aynı yönde olduğu belirlenmiştir.

ALUAE X BMAE interaksiyonlarında LSD \%5 seviyesinde dip kök kuru ağırlık değerleri önemli bulunmuştur. En yüksek değeri Sy-VAM'ın ALUAE X U3 uygulaması (12.97 g) vermiştir (Şekil 4). Razakı çeşidinde ise Sh-VAM X U4 interaksiyonu (8.12 g) en yüksek değeri almıştır. Korkutal ve ark. (2018)'nın biyolojik materyal uygulamasının dip kök kuru ağırlığını artırdığı bulgusuyla araştırmamız sonuçlarının Razakı çeşidinde paralellik gösterdiği belirlenmiştir.

A. Lavelleé çeşidinde kökteki en yüksek N, \%1.60 değeri ile Sh-VAM x U4; Razakı çeşidinde ise Sy-VAM $x$ U4 interaksiyonunda (\%1.68) tespit edilmiştir. Razakı çeşidinde fosfor oranı birden fazla interaksiyonda en yüksek değerleri \%0.17 almıştır. A. Lavelleé çeşidinde de aynı rakamsal değer

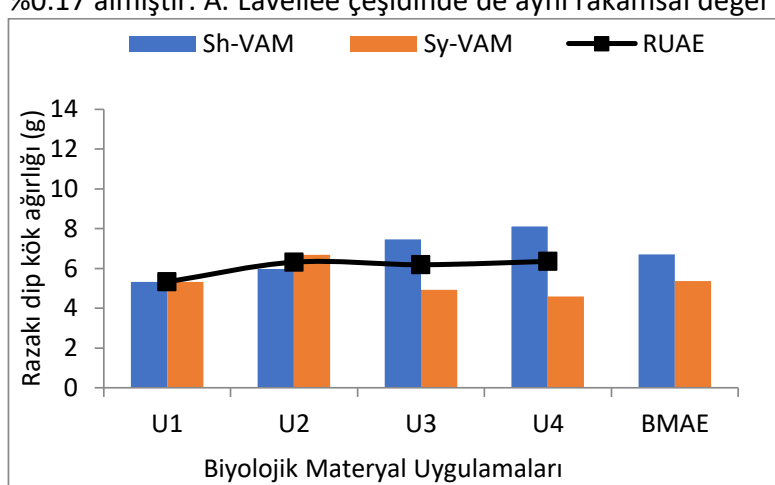

elde edilmiştir. Augin ve ark. (2004)'nın köklerde yeterli fosfor seviyesinin G. aggregatum uygulaması ile alındığı bulgusu denememizle paraleldir. Razakı çeşidinde Potasyum oranını en yüksek veren interaksiyon Sy-VAM x U3 (\%1.10) olmuştur. A. Lavelleé çeşidinde ise Sh-VAM x U1 interaksiyonu en yüksek değeri (\%1.15) vermiştir. Balestrini ve ark. (2017)'nın mikoriza uygulamasıyla kökteki $P$ ve $K$ konsantrasyonları arasında istatistiki olarak önemli bir fark bulunmadığını belirttikleri bulgusu ile sonuçlarımızın benzer yönde olduğu görülmüştür.

Razakı çeşidinde kökte en yüksek Ca oranının Sy-VAM x U3 interaksiyonunda (\%1.50) olduğu tespit edilmiştir. A. Lavelleé çeşidinde en yüksek değer \%1.86 kalsiyum ile ShVAM x U4 interaksiyonundan alınmıştır. Kökte Mg açısından Razakı çeşidinde Sy-VAM x U3 interaksiyonunun (\%0.24), A. Lavelleé çeşidinde ise Sh-VAM x U4 interaksiyonunun en yüksek değeri (\%0.31) aldığı ortaya konmuştur (Şekil 5 ve Şekil 6). Fe (ppm) içeriği bakımından A. Lavalleé çeşidinde Sy-VAM x U2 (644 ppm); Razakı çeşidinde de Sy-VAM x U2 interaksiyonu (588 ppm) en yüksek değeri verdiği tespit edilmiştir. Cu (ppm) miktarına A. Lavelleé çeşidinde Sh-VAM x U1 (21 ppm) interaksiyonunun artırıcı bir etki yaptığı söylenebilir. Zn miktarı açısından A. Lavelleé Sh-VAM x U2 (16 ppm); Razakı ise Sh-VAM x U4 (12,70 ppm) en yüksek değeri veren interaksiyonlar olmuştur. $\mathrm{Mn}$ içeriği

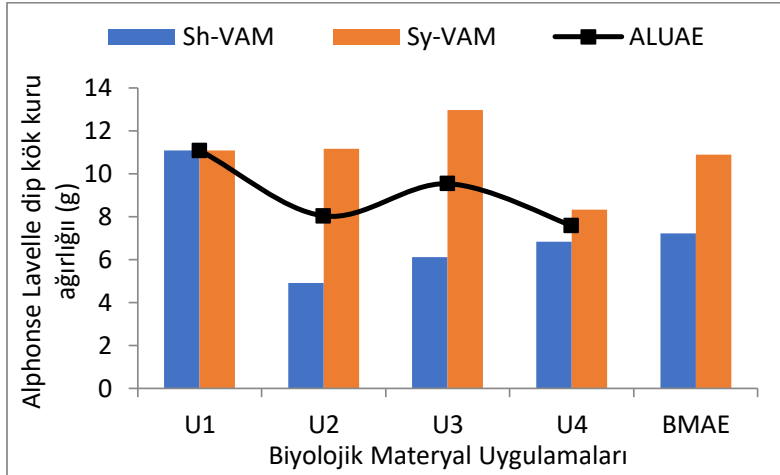

Şekil 4. Her iki mikoriza uygulamasının Razakı ve A. Lavalleé çeşitlerinin dip kök kuru ağırlığı etkileri [Sh-VAM: U 1 (Kontrol=VAM yok). U 2 (Harca VAM). U 3 (Fidana VAM). U 4 (Harca+Fidana VAM); Sy-VAM: U 1 (Kontrol=VAM yok). U 2 (Harca VAM). U 3 (Fidana VAM). U 4 (Harca+Fidana VAM)]

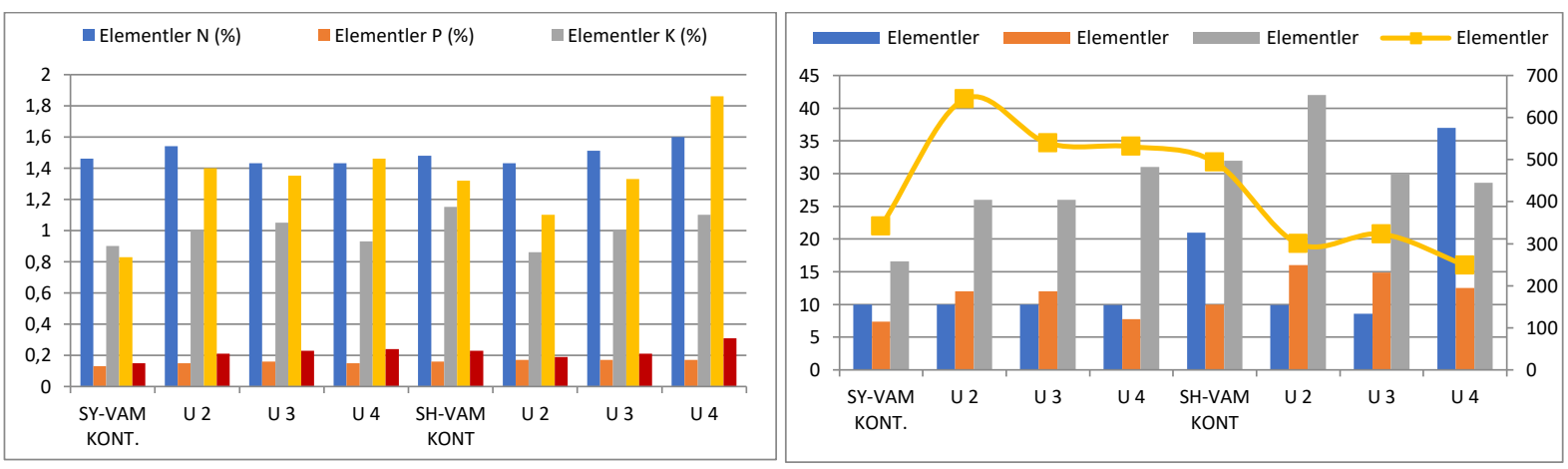

Şekil 5. Her iki mikoriza uygulamasının A. Lavelleé üzüm çeşidinde kök mineral madde analizine etkileri 


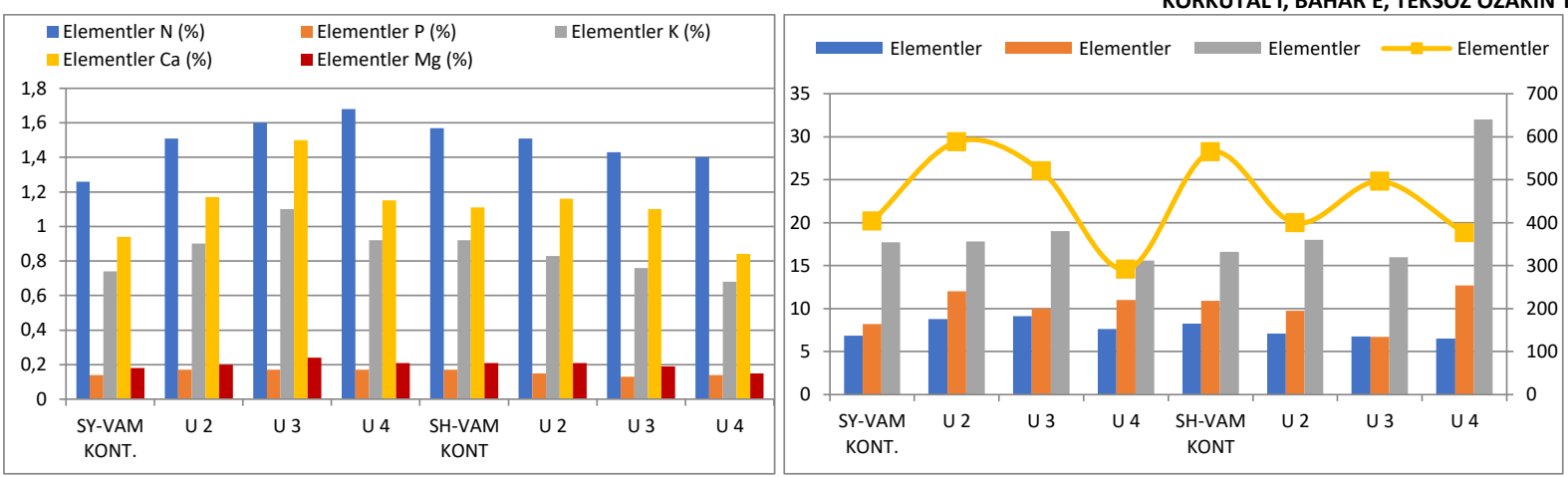

Şekil 6. Her iki mikoriza uygulamasının Razakı üzüm çeşidinde kök mineral madde analizine etkileri

incelendiğinde A. Lavelleé çeşidinde Sh-VAM x U2 (42 ppm); Razakı çeşidinde ise Sh-VAM x U4 interaksiyonunun (32 ppm) en yüksek değer verdiği belirlenmiştir (Şekil 5 ve Şekil 6).

\section{SONUÇ}

Mikorizaların etkileri A. Lavalleé/1103P ve Razakı/1103P aşı kombinasyonlarında araştırılmış ve Symbion VAM ve Shubhodaya VAM'ın farklı uygulama şekillerinin 1 yaşındaki fidanların çap, sürgün ve kök özellikleri üzerine etkileri belirlenmiştir.

A. Lavalleé çeşidinde biyolojik materyal uygulama şekillerinden fidan özelliklerine en çok etkili olan U2 (harca mikoriza) uygulamasıdır. Razakı çeşidinde, ise en etkili olanların U3 ve U4 uygulamaları olduğu belirlenmiştir. İyi bir kök yapısı için dikkate alınan kök kuru ağırığı; aşılama için en uygun kriter olan gövde çapı ve iyi bir fidanın göstergesi olan kalem çapı ölçümlerinde A. Lavalleé çeşidi için kontrol en olumlu etkiye sahip bulunmuştur. Kısacası A. Lavalleé çeşidinde fidan özelliklerini iyileştirmek için herhangi bir mikoriza uygulamasına gerek olmadığı sonucuna varılmıştır. Razakı çeşidinde ise fidan özelliklerini iyileştirmede Shubhodaya VAM uygulamasının kontrolden daha olumlu etkileri olduğu tespit edilmiştir. Buradan görüldüğü üzere çeşit önemli bir faktördür. Mikorizalar kurağa dayanımı artırarak sürgün ve kök gelişimini kontrole nazaran baskı altında tutmuşlardır. Ancak mikoriza uygulamalarının maliyetinin çok yüksek olduğu da gözardı edilmemelidir. Ayrıca dikimden ne kadar süre sonra mikorizaların toprağa yerleştiği ve faydalı etki gösterdiği de çok önemlidir.

\section{KAYNAKLAR}

Anzanello R, Souza PVD de, Casamali B (2011) Use of arbuscular mycorrhizal AMF fungi in micropropagated grape rootstocks. Bragantia-Revista de Ciências Agronômicas 70(2): 409-415. doi: 10.1590/S000687052011000200023

Augin O, Mansilla JP, Vilariño A, Sainz MJ (2004) Effects of mycorrhizal inoculation on root morphology and nursery production of three grapevine rootstocks. ASEV 55(1): 108-111.

Balestrini R, Salvioli A, Molin AD, Novero M, Gabelli G, Paparelli E, Marroni F, Bonfante P (2017) Impact of an arbuscular mychorrizal fungus versus a mixed microbial inoculum on the transcriptome re- programming of grapevine roots. Mychorriza 27: 417430. doi: 10.1007/s00572-016-0754-8

Bavaresco L, Gatti M, Zamboni M, Fogher C (2010) Role of artificial mycorrhization on iron uptake in calcareous soil, on stilbene root synthesis and in other physiological processes in grapevine. Proceedings of $33^{\text {rd }}$ World Congress of Vine and Wine. (Tbilisi, 20-25 Giugno 2010), OIV, p. 101-107.

Bayram A (2000) Bazı mikoriza türlerinin Amerikan asma fidanlarının kök ve sürgün gelişimi üzerine etkileri. Kahramanmaraş Sütçü İmam Üniversitesi Fen Bilimleri Enstitüsü, Yüksek Lisans Tezi, Kahramanmaraş.

Çelik H (2019) Türkiye bağcılığı ve asma fidanı üretimi-Dış ticareti ile ilgili stratejik bir değerlendirme. http://www.hasancelik.web.tr/Yayinlar/124.pdf, Erişim tarihi: 11.01.2019.

Düzgüneş O, Kesici T, Gürbüz F (1983) İstatistik Metodları I. Ankara Üniversitesi Ziraat Fakültesi Yayınları, No: 229. Ankara. 218s.

Eichhorn KW, Lorenz DH (1977) Phänologische Entwicklungsstadien der Rebe. Nachrichtenbl. Deut. Pflanzenschutz. 29: 119-120.

Eftekhari M, Alizadeh M, Mashayekhi K, Asghari H, Kamkar B (2010) Integration of Arbuscular Mycorrhizal Fungi to grapevine (Vitis vinifera L.) in nursery stage. Journal of Advanced Laboratory Research in Biology 1(2): 102111.

Eroğlu D (2014) Bazı üzüm çeşitlerinin aşılı tüplü fidan üretimlerinde farklı biyolojik preparat uygulamalarının etkileri. Adnan Menderes Üniversitesi. Yüksek Lisans Tezi, Aydın.

Eroğlu D, Çelik M (2015) Bazı üzüm çeşitlerinin aşılı asma fidanı üretiminde mikoriza uygulamalarının etkileri. Selçuk Tarım ve Gıda Bilimleri Dergisi A. 27 (Türkiye 8. Bağcılık ve Teknolojileri Sempozyumu Özel Sayısı), s. 48-55.

Gendiah HM (1991) Stimulating root growth of grape hardwood cuttings by using endomychorrizal fungi. Annals of Agriculture Science Moshtohor 29(4): 17111723.

Kara Z, Özer A, Sabır A (2011a) Bazı asma yoz ve çeliklerinin vejetatif gelişmesine mikorizal preparasyon uygulamalarının etkileri. Türkiye 6. Bahçe Bitkileri Kongresi, Şanlıurfa, s. 33-40. 
Kara Z, Söylemezoğlu G, Çakır A, Sabır A, Shifdar M (2011b) Aşı asma fidanı üretiminde mikorizal preparasyon (MP, Biovam) uygulamalarının etkileri. Türkiye 6 . Bahçe Bitkileri Kongresi, Şanlıurfa, s. 41-46.

Kara Z, Bağçevli A (2012) Bazı simbiyotik mikroorganizma karışımı uygulamalarının farklı asma anacı çeliklerinde bitki gelişimi üzerine etkileri. Selçuk Tarım ve Gıda Bilimleri Dergisi 26(3): 20-28.

Karagiannidis N, Nikolaou N, Mattheou A (1995) Influence of three arbuscular mycorrhiza species on the growth and nutrient uptake of three grapevine rootstocks and one table grape cultivar. Vitis 34(2): 85-89.

Kavak O (2006) Aşılı köklü tüplü asma fidanı üretiminde fidan kalite özelliklerine mycorrhiza ve humik asit uygulamalarının etkileri. Selçuk Üniversitesi Fen Bilimleri Enstitüsü, Yüksek Lisans Tezi, Konya.

Kılıç D (2014) Kokteyl mikoriza uygulamalarının aşıı asma fidanı üretiminde fidan randıman ve kalitesi üzerine etkileri. Gazi Osmanpaşa Üniversitesi Fen Bilimleri Enstitüsü, Doktora Tezi, Tokat.

Korkutal I, Bahar E, Mahmood MNAM (2018) 110R Anacına aşılı Merlot üzüm çeşidi genç omcalarına farklı dozlarda uygulanan Trichoderma harzianum ve Bacillus subtilis' in II. Söküm dönemindeki etkileri. ADÜ Ziraat Fakültesi Dergisi 15(2): 67-75.

Mattheou A, Karagiannidis N, Nikolaou N (1994) Seasonal changes of leaf nutrient leves of grapevine over two dry years. Agricultura Mediterranea 124(2-3): 187196.
Meyer AH, Botha A, Valentine AJ, Acher E, Louw PJE (2005) The occurrence and infectivity of arbuscular mycorrhizal fungi in inoculated and uninoculated rhizosphere soils of two-year-old commercial grapevines. South African Journal of Enology and Viticulture 26: 90-94. doi: 10.21548/26-2-2123

Mstat-C (1989) A Microcomputer Program for the Design, Management, and Analysis of Agronomic Research Experiments. Michigan State University - USA.

Nogales A, Luque J, Estaún V, Camprubí A, Garcia-Figueres F, Calvet C (2009) Differential growth of mycorrhizal field-inoculated grapevine rootstocks in two replant soils. ASEV 60(4): 484-489.

Özdemir G, Akpinar C, Sabir A, Bilir H, Tangolar S, Ortas I (2010) Effect of inoculation with mycorrhizal fungi on growth and nutrient uptake of grapevine genotypes (Vitis spp.). European Journal of Horticultural Science 75: 103-110.

Özer A (2011) Tohum ve çelikten elde edilen genç asmalarda mikorizal preparasyon uygulamalarının etkileri. Selçuk Üniversitesi Fen Bilimleri Enstitüsü, Yüksek Lisans Tezi, Konya.

Schreiner RP, Linderman RG (2005) Mycorrhizal colonization in dryland vineyards of the Willamette Valley-Oregon. Small Fruits Review 4(3): 41-55. doi: 0.1300/J301v04n03_04. 